Si ze- sel ect i ve encapsul at i on property of uni mol ecul ar reverse mi cel I e consi sting of hyper br anched D gl ucan core and L-I euci ne ethyl ether shel I

\begin{tabular}{|l|l|}
\hline 著者 & $\begin{array}{l}\text { Sat oh Toshi fumi, Ki taj yo Yoshi kazu, Sakai } \\
\text { Ryosuke, Nar umi At sushi, Takahashi Kenj i, Kaga } \\
\text { Har um, Kaneko Nor i aki, Kakuchi Toyoj i }\end{array}$ \\
\hline $\begin{array}{l}\text { j our nal or } \\
\text { publ i cat i on t i t l e }\end{array}$ & Necronml ecul ar Symposi a \\
\hline vol une & 279 \\
\hline number & 1 \\
\hline page r ange & $145-150$ \\
\hline year & $2009-05-01$ \\
\hline URL & ht t p: //hdl . handl e. net /2297/18711 \\
\hline
\end{tabular}




\title{
Size-Selective Encapsulation Property of Unimolecular Reverse Micelle Consisting of Hyperbranched D- Glucan Core and L-Leucine Ethyl Ether Shell
}

\author{
Toshifumi Satoh, ${ }^{1, *}$ Yoshikazu Kitajyo, ${ }^{1}$ Ryosuke Sakai, ${ }^{1}$ Atsushi Narumi, ${ }^{2}$ \\ Kenji Takahashi, ${ }^{3}$ Harumi Kaga, ${ }^{4}$ Noriaki Kaneko, ${ }^{5}$ Toyoji Kakuchi ${ }^{1}$ \\ ${ }^{1}$ Division of Biotechnology and Macromolecular Chemistry, Graduate School \\ of Engineering, Hokkaido University, Sapporo, 060-8628, Japan \\ Fax: (+81)11 7066603; E-mail: satoh@poly-bm.eng.hokudai.ac.jp \\ ${ }^{2}$ Department of Polymer Science and Engineering, Graduate School of \\ Science and Engineering, Yamagata University, Yonezawa 992-8510, Japan \\ ${ }^{3}$ Division of Material Science, Graduate School of Natural Science and \\ Technology, Kanazawa University, Kanazawa, 920-1192, Japan \\ ${ }^{4}$ National Institute of Advanced Industrial Science and Technology (AIST), \\ Sapporo, 062-8517, Japan; \\ ${ }^{5}$ MACROTEC Co., Sapporo 062-8517, Japan
}

Summary: The synthesis of a unimolecular reverse micelle (3) consisting of hyperbranched D-glucan as the core and L-leucine ethyl ester as the shell was accomplished through the carbamation reaction of the hyperbranched D-glucan (1) with the $N$-carbonyl L-leucine ethyl ester (2) in pyridine at $100{ }^{\circ} \mathrm{C}$. The polymer 3 was soluble in a large variety of organic solvents, such as methanol, acetone, chloroform, and ethyl acetate, and insoluble in water, which remarkably differed from the solubility of $\mathbf{1}$. The solubilities of $\mathbf{3}$ were also changed by the substitution degrees of the L-leucine moiety. The encapsulation ability of $\mathbf{3}$ toward water-soluble dyes has been investigated. These results indicated that $\mathbf{3}$ was a unimolecular reverse micelle with an encapsulation ability toward hydrophilic dye molecules. In addition, $\mathbf{3}$ showed an molecular size-selective encapsulation ability.

Keywords: amphiphiles; core-shell polymers; micelle; encapsulation

\section{Introduction}

Due to its three-dimensional spherical structure, amphiphilic macromolecules with a coreshell morphology is an attractive nano-scale material. An amphiphilic structure consisting of a covalently linked dendritic core and shell parts promises to be a unimolecular micelle in solution, which could stably exist under various conditions, such as when the concentration, temperature, and $\mathrm{pH}$ were significantly changed. ${ }^{[1-4]}$ The high stability as a unimolecular micelle is produced in a certain cavity in the interior of the spherical amphiphile, and this space could encapsulate suitable guest molecules. Therefore, there have been many studies on the design and synthesis of amphiphilic dendrimers as 
nanomaterials, such as a drug delivery agents, ${ }^{[5-10]}$ nanoreactors, ${ }^{[11-16]}$ and nanocapsules. ${ }^{[17-}$ 22]

Hyperbranched polymers are the preferable building blocks as the core of such amphiphiles because they possess a three-dimensional spherical architecture with numerous functional groups located on the exterior of the molecules. Furthermore, they can be easily synthesized in a one-pot process; hence, amphiphilic hyperbranched polymers have potential applications for practical use. Thus, it is interesting to use hyperbranched polymers as the key starting materials for the preparation of a spherical amphiphile with a unimolecular miceller property. ${ }^{[23-32]}$

Recently, we reported that some unimolecular reverse micelles consisting of a hydrophilic hyperbranched polycarbohydrate core and hydrophobic shell possessed an encapsulation ability for hydrophilic guest molecules and the controlled release property of the encapsulated guest molecules, ${ }^{[30-32]}$ e.g., the biodegradable unimolecular reverse micelle consisting of a hyperbranched D-mannan core and a poly(L-lactide) shell, ${ }^{30]}$ and the $\mathrm{pH}$ sensitive unimolecular reverse micelle consisting of a hyperbranched D-glucan core and Lleucine ethyl ether shell. ${ }^{[31]}$

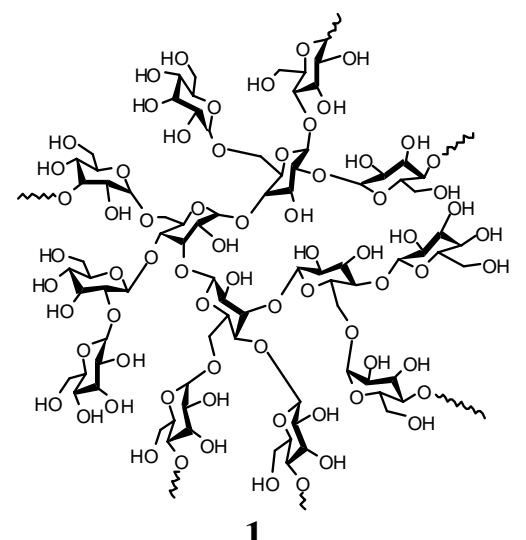

1

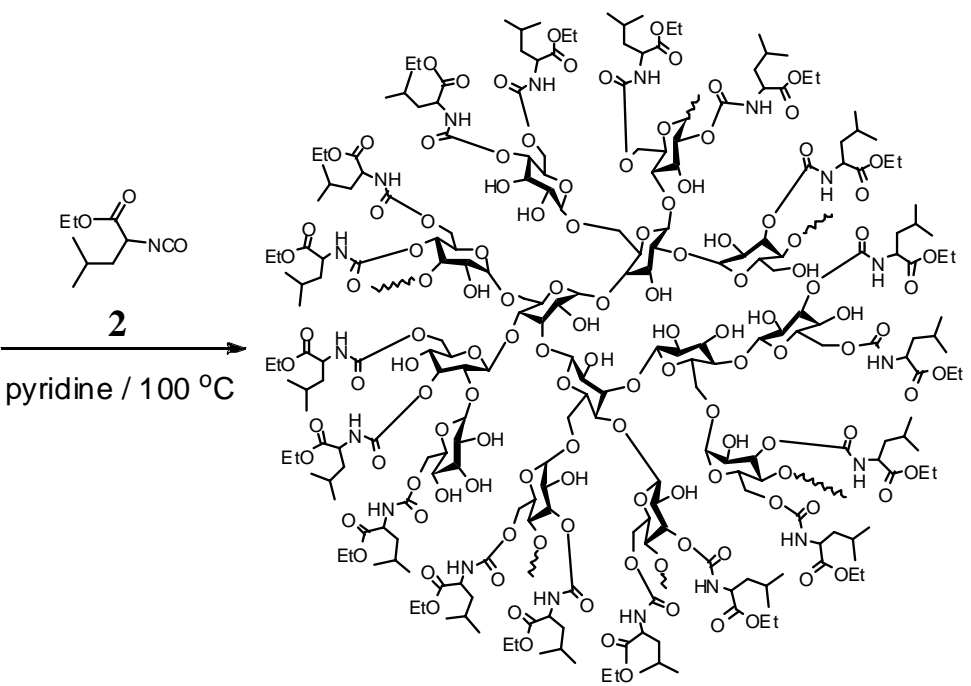

3

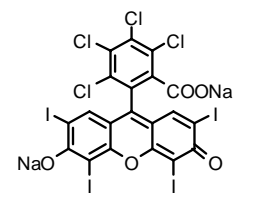

Rose bengal (RB)

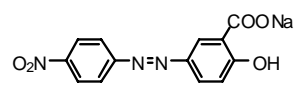

Alizarin yellow (AY)

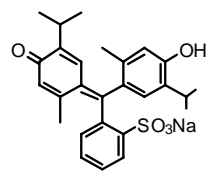

Thymol blue (TB)

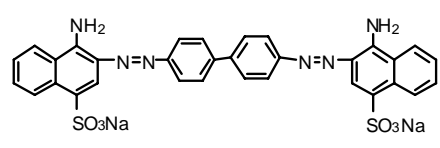

Congo red (CR)

Figure 1. Synthesis of unimolecular reverse micelle consisting of hyperbranched D-glucan core and L-leucine ethyl ester shell.

Thus, of great interest is the functional extension of a unimolecular reverse micelle with a 
hyperbranched polycarbohydrate core. We now report the size-selective encapsulation ability of a unimolecular reverse micelle (3) consisting of a hyperbranched D-glucan core and L-leucine ethyl ester shell. In addition, the unpublished characteristics of 3, such as solubility and mass analysis, are reported.

\section{Characteristics of Hyperbranched D-glucan with L-leucine Moieties}

In order to prepare the hyperbranched D-glucan with the L-leucine moiety (3), the reaction of the hyperbranched D-glucan $\left(1, M_{\mathrm{w}}=70600\right)$ with the $N$-carbonyl L-leucine ethyl ester (2) was carried out in pyridine at $100{ }^{\circ} \mathrm{C}$, as described in a previous report (Figure 1). ${ }^{[31]}$ The degrees of substitution (DS) determined by an elemental analysis could be easily controlled by the feed rate of $\mathbf{2}$, and these values gradually increased with the increasing molar ratio of $\mathbf{2}$ and the D-glucose units in 1. The solubilities of the resulting polymers 3 were compared with polymer $\mathbf{1}$ in Table 1 . The hyperbranched D-glucan $\mathbf{1}$ is soluble in water and insoluble in organic solvent. In contrast, the obtained polymers $\mathbf{3}$ are soluble in a large variety of organic solvents, such as methanol, acetone, chloroform, and ethyl acetate, and insoluble in water, which remarkably differed from the solubility of $\mathbf{1}$. The solubilities of 3 were also changed by the substitution degrees (DS) of the L-leucine moiety. 3b and 3c with a DS of $68.7 \%$ and $93.7 \%$, respectively, are soluble in ethyl acetate, diethyl ether, and toluene, while 3a with a DS of $46.0 \%$ is insoluble in these solvents.

Table 1, Solubilities of hyperbranched D-glucan (1) and the hyperbranched D-glucan with L-leucine moiety (3). ${ }^{\text {a) }}$

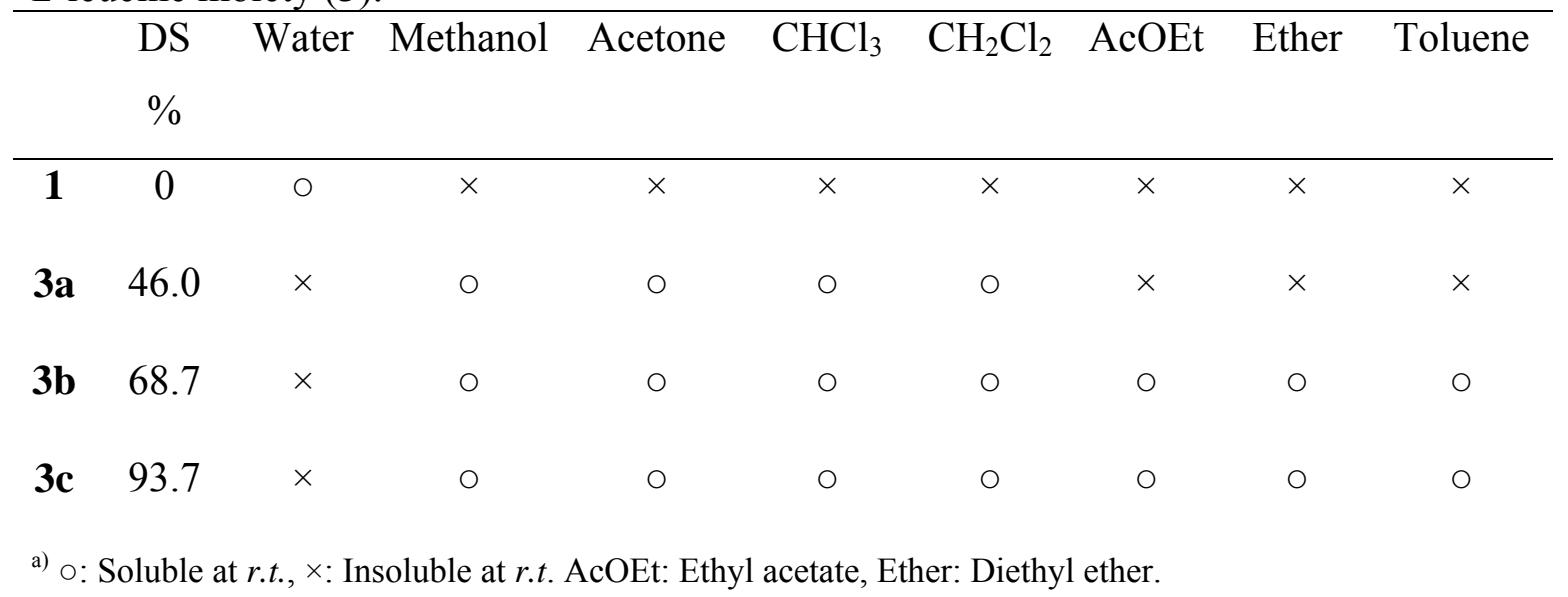




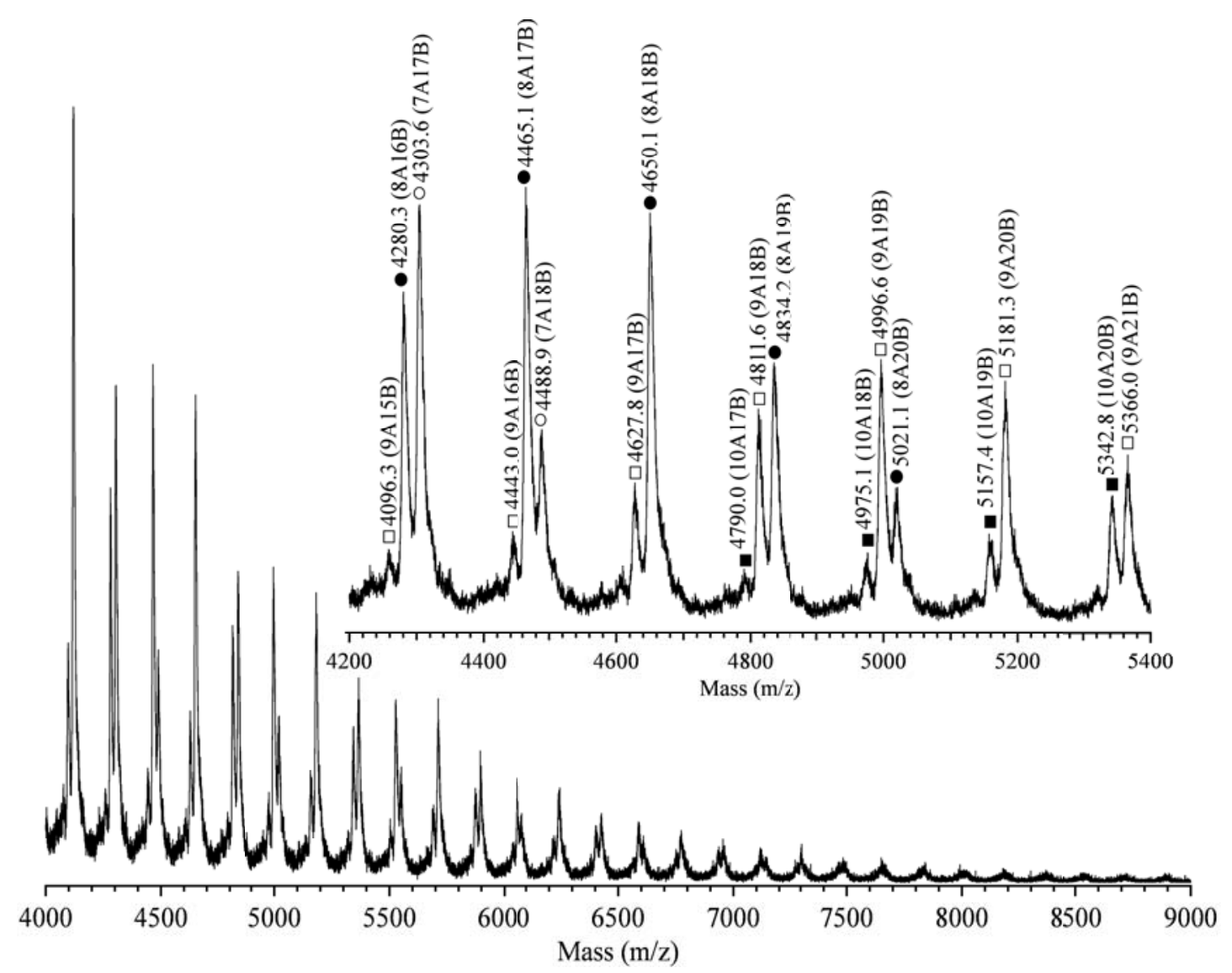

Figure 2. MALDI-TOF mass spectrum of $3 \mathbf{b}$ with DS of $68.7 \%$. Samples were prepared by mixing the polymer $\left(10 \mathrm{mg} \cdot \mathrm{mL}^{-1}, 2 \mu \mathrm{L}\right)$ and a matrix (2,5-dihydroxybenzoic acid, 10 $\mathrm{mg} \cdot \mathrm{mL}^{-1}, 20 \mu \mathrm{L}$ ) in methanol. The symbols " $\mathrm{A}$ " and "B" denote the number of D-glucose units and L-leucine ethyl ether moieties in 3b, respectively, e.g., 10A20B is the polymer consisting of ten D-glucose units and twenty L-leucine ethyl ether units. The open circles, closed circles, open square, and closed square correspond to $\mathrm{A}=7,8,9$, and 10, respectively. In the conditions, the polymers having an ca. $9000 \mathrm{~m} / \mathrm{z}$ can be detected as maximum.

In order to confirm the polymer structure of $\mathbf{3}$ in detail, the matrix-assisted laser desorption ionization time-of-flight mass spectrometry (MALDI-TOF-MS) measurement of $\mathbf{3 b}$ was performed using 2,5-dihydroxybenzoic acid as the matrix. A typical spectrum is shown in Figure 2. In the mass spectrum, there are some series of peaks with a regular interval of ca. $185 \mathrm{~m} / \mathrm{z}$ which was equal to the molar mass of the L-leucine ethyl ester moiety. For example, the peaks denoted by the closed circles in Figure 2 have a regular interval and correspond to $n \times 185+8 \times 162$ (D-glucose unit) $+23(\mathrm{Na})$. In the same way, the peaks marked by the open squares correspond to $n \times 185+9 \times 162+23$, meaning that the polymer consists of nine D-glucose units and $n$ L-leucine ethyl ester moieties. The 
open circles and closed squares in Figure 2 also correspond to the series of seven and ten D-glucose units, respectively. Therefore, these spectroscopic results indicated that the product for the carbamation reaction of $\mathbf{1}$ with $\mathbf{2}$ was assignable to the hyperbranched Dglucan with the L-leucine moieties, 3.

\section{Encapsulation property of 3}

In order to study the unimolecular reverse micelle property of 3 , we examined the encapsulation characteristics for the water-soluble dyes, rose bengal (RB), alizarin yellow (AY), and thymol blue (TB), using the solid/liquid phase transfer method. The watersoluble dye as a solid was added to the chloroform solutions containing $\mathbf{3 b}$, and the heterogeneous mixtures were then shaken for $24 \mathrm{~h}$ at $37{ }^{\circ} \mathrm{C}$. After removal of any undissolved dye using $0.45 \mu \mathrm{m}$ membrane filters, the chloroform phases were apparently colorized, as shown in Figure 3. In contrast, the control experiment in the absence of $\mathbf{3 b}$ showed no coloration. These results showed that $\mathbf{3 b}$ was a unimolecular reverse micelle with an encapsulation ability toward hydrophilic dye molecules. On the contrary, congo red (CR), which had a significantly extended structure than the other dyes, was not encapsulated. The result indicated that the encapsulation ability of $\mathbf{3 b}$ should relate to the molecular size of the dye, that is, the space needed for encapsulating CR was insufficient in $3 \mathbf{b}$.
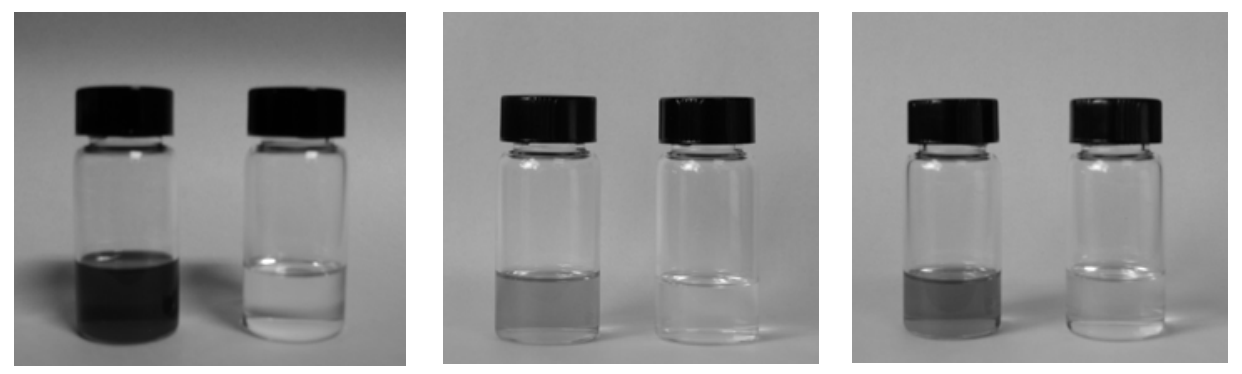

Figure 3. Demonstration of the encapsulation property of $\mathbf{3 b}$ in $\mathrm{CHCl}_{3}$ toward rose bengal (left), alizarin yellow (center), and thymol blue (right). The left vials in each picture include $\mathbf{3 b}$, while the right vials are the control experiment in the absence of $\mathbf{3 b}$.

In order to study the selectivity for the encapsulation ability of $\mathbf{3}$, the encapsulation characteristics toward the mixed dyes was examined using the solid/liquid phase transfer method. Figure 4 shows the UV-vis spectra of the chloroform solutions for the RB/ $\mathbf{3 b}$, 
$\mathrm{TB} / \mathbf{3 b}$, and $(\mathrm{RB}+\mathrm{TB}) / \mathbf{3 b}$ systems. For the $(\mathrm{RB}+\mathrm{TB}) / \mathbf{3 b}$ mixed system, the characteristic absorptions due to RB and TB appeared in the visible region of $500-600 \mathrm{~nm}$ and 360 $500 \mathrm{~nm}$, respectively, as shown in Figure 4a. The encapsulation amounts of hydrophilic dyes per $3 \mathbf{b}([\mathrm{Dye}] /[3])$ were determined from the UV-vis spectra of the $(\mathrm{RB}+\mathrm{TB}) / \mathbf{3 b}$ system diluted with DMSO. The experimental results are summarized in Table 2. In the experiment, TB was more efficiently encapsulated in $\mathbf{3 b}$ than $\mathrm{RB}$, e.g., $[\mathrm{RB}] /[3 \mathbf{b}]$ of 8.7 and $[\mathrm{TB}] /[3 \mathbf{b}]$ of 15.5 . In contrast, the encapsulation experiment using the $(\mathrm{RB}+\mathrm{AY}) / 3 \mathbf{b}$ mixed system showed that RB was encapsulated more efficiently than AY, e.g., $[R B] /[3 b]$ of 17.6 and $[\mathrm{AY}] /[3 \mathbf{b}]$ of 11.5 . These results indicated that $\mathbf{3 b}$ has a molecular sizeselective encapsulation property and the order of the selectivity is $\mathrm{TB}>\mathrm{RB}>\mathrm{AY}$, which is the reverse order of the major axis of the dyes, i.e., TB $(12.5 \AA)<\mathrm{RB}(13.2 \AA)<\mathrm{AY}$ $(14.1 \AA)$.

Figure $4 \mathrm{~b}$ shows the $\mathrm{UV}$-vis spectrum of the chloroform solution for the $(\mathrm{RB}+\mathrm{CR}) / 3 \mathbf{b}$ mixed system. The spectrum showed that only RB was encapsulated in $\mathbf{3 b}$, indicating that 3b has a size-selective encapsulation ability, i.e., $\mathbf{3 b}$ can preferentially encapsulate small molecules from the mixture.

a)

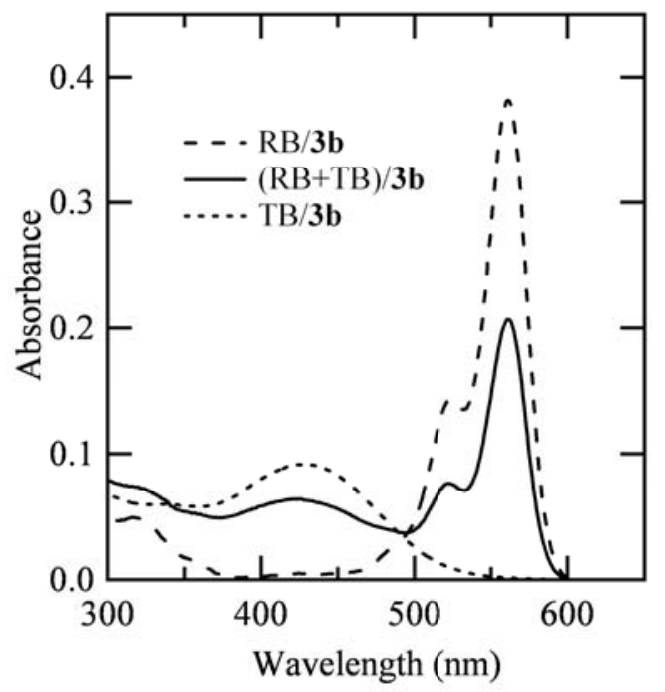

b)

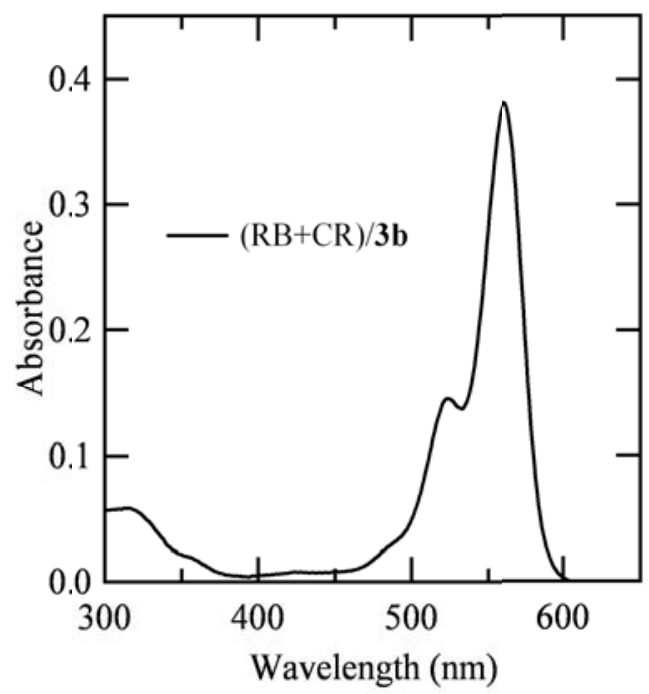

Figure 4. UV-vis spectra of a) $R B / 3 \mathbf{b}, T B / 3 \mathbf{b}$, and $(R B+T B) / 3 b$ systems and $b$ ) $(\mathrm{RB}+\mathrm{CR}) / 3 \mathbf{b}$ system. Conditions of $(\mathrm{RB}+\mathrm{TB}) / 3 \mathbf{b}$ system; $3 \mathbf{b}: 11 \mathrm{mg}$, RB: ca. $10 \mathrm{mmol}$, TB: ca. $10 \mathrm{mmol}, 2 \mathrm{~mL} \mathrm{CHCl}$. After shaking for $24 \mathrm{~h}$ at $37{ }^{\circ} \mathrm{C}$, any insoluble dyes were removed using a $0.45 \mu \mathrm{m}$ membrane filter. 
Table 2. Encapsulation amounts of hydrophilic dyes per $\mathbf{3 b}$.

\begin{tabular}{cccc}
\hline & {$[\mathrm{RB}] /[3 \mathbf{b}]$} & {$[\mathrm{TB}] /[3 \mathbf{b}]$} & {$[\mathrm{AY}] /[3 \mathbf{b}]$} \\
\hline $\mathrm{RB}$ and TB & 8.7 & 15.5 & - \\
$\mathrm{RB}$ and AY & 17.6 & - & 11.5
\end{tabular}

a) The encapsulation amounts of the hydrophilic dyes per $\mathbf{3 b}([\mathrm{Dye}] /[3 \mathbf{b}])$ were determined by quantitative analysis of the UV-vis spectra of the Dye/3b system diluted with DMSO (rose bengal (RB), $\mathrm{CHCl}_{3} / \mathrm{DMSO}=1 / 7(\mathrm{v} / \mathrm{v}), \lambda_{\max }=565 \mathrm{~nm}, \varepsilon_{\max }=1.47 \times 10^{5} \mathrm{~mol}^{-1} \cdot \mathrm{L}^{-\mathrm{cm}^{-1}}$; thymol blue (TB), $\mathrm{CHCl}_{3} / \mathrm{DMSO}=1 / 7(\mathrm{v} / \mathrm{v}), \lambda_{\max }=391 \mathrm{~nm}, \varepsilon_{\max }=1.41 \times 10^{4} \mathrm{~mol}^{-1} \cdot \mathrm{L} \cdot \mathrm{cm}^{-1} ;$ alizarin yellow (AY), $\left.\mathrm{CHCl}_{3} / \mathrm{DMSO}=1 / 1(\mathrm{v} / \mathrm{v}), \lambda_{\max }=369 \mathrm{~nm}, \varepsilon_{\max }=1.67 \times 10^{4} \mathrm{~mol}^{-1} \cdot \mathrm{L} \cdot \mathrm{cm}^{-1}\right)$.

\section{Conclusion}

The unimolecular reverse micelle (3) consisting of hyperbranched D-glucan (1) as the core and the L-leucine ethyl ester as the shell was synthesized by the reaction of 1 with the $N$ carbonyl L-leucine ethyl ester. $\mathbf{3}$ is soluble in a large variety of organic solvents, such as methanol, acetone, chloroform, and ethyl acetate, and insoluble in water, which remarkably differed from the solubility of $\mathbf{1}$. The solubilities of $\mathbf{3}$ were also changed by the substitution degrees of the L-leucine moiety. The encapsulation ability of $\mathbf{3}$ toward water-soluble dyes has been investigated. These results indicated that $\mathbf{3}$ was a unimolecular reverse micelle with an encapsulation ability toward hydrophilic dye molecules. In addition, $\mathbf{3}$ showed a molecular size-selective encapsulation ability. Hence, 3 can be used as an effective tool for separation systems of mixture.

\section{Acknowledgment}

This study was supported by the Industrial Technology Research Grant Program in 2007 from the New Energy and Industrial Technology Development Organization (NEDO) of Japan. The authors thank the Open Facility (Hokkaido University Sousei Hall) for the polymer characterization.

[1] C. N. Moorefield, G. R. Newkome, C R Chimie 2003, 6, 715.

[2] U. Gupta, H. B. Agashe, A. Asthana, N. K. Jain. Biomacromolecules 2006, 7, 649.

[3] M. W. P. L. Baars, E. W. Meijer, Top Curr. Chem. 2000, 210(Dendrimers II), 131.

[4] C. J. Hawker, K. L. Wooley, J. M. J. Fréchet, J. Chem. Soc., Perkin Trans. 1 1993, 12, 1287.

[5] D. Chandrasekar, R. Sistla, F. J. Ahmad, R. K. Khar, P. V. Diwan, Biomaterials 2007, $28,504$.

[6] R. S. Dhanikula, P. Hildgen, Bioconjugate Chem. 2006, 17, 29.

[7] C. M. Paleos, D. Tsiourvas, Z. Sideratou, L. Tziveleka, Biomacromolecules 2004, 5, 524.

[8] C. Kojima, K. Kono, K. Maruyama, T. Takagishi, Bioconjugate Chem. 2000,11, 910.

[9] M. Liu, K. Kono, J. M. J. Fréchet, J. Controlled Release 2000, 65, 121.

[10] Z. Sideratou, D. Tsiourvas, C. M. Paleos, Langmuir 2000, 16, 1766.

[11] A. W. Jensen, B. S. Maru, X. Zhang, D. K. Mohanty, B. D. Fahlman, D. R. Swanson, D. A. Tomalia, Nano Lett. 2005, 5, 1171. 
[12] T. Mizugaki, Y. Miyauchi, M. Murata, K. Ebitani, K. Kaneda, Chem Lett. 2005, 34, 286.

[13] M. Ooe, M. Murata, T. Mizugaki, K. Ebitani, K. Kaneda, Nano Lett. 2002, 2, 999.

[14] L. K. Yeung, R. M. Crooks, Nano Lett. 2001, 1, 14.

[15] M. E. Piotti, F. Rivera, R. Bond, C. J. Hawker, J. M. J. Frechet, J. Am. Chem. Soc. 1999, 121, 9471.

[16] S. Hecht, J. M. J. Fréchet, J. Am. Chem. Soc. 2001, 123, 6959.

[17] A. D. Morara, R. L. McCarley, Org Lett. 2006, 8, 1999.

[18] S. K. Ghosh, S. Kawaguchi, Y. Jinbo, Y. Izumi, K. Yamaguchi, T. Taniguchi, K. Nagai, K. Koyama, Macromolecules 2003, 36, 9162.

[19] V. Chechik, M. Zhao, R. M. Crooks, J. Am. Chem. Soc. 1999, 121, 4910.

[20] J. F. G. A. Jansen, E. W. Meijer, E. M. M. de Brabander-van den Berg, J. Am. Chem. Soc. 1995, 117, 4417.

[21] J. F. G. A. Jansen, E. M. M de Brabander van den Berg, E. W. Meijer. Science 1994, 266, 1226.

[22] K. Tsutsumiuchi, K. Aoi, M. Okada. Polym. J. 1999, 31, 935.

[23] A. Sunder, M. Krämer, R. Hanselmann, R. Mülhaupt, H. Frey, Angew. Chem. Int. Ed. 1999, 38, 3552.

[24] S-E. Stiriba, H. Kautz, H. Frey, J. Am. Chem. Soc. 2002, 124, 9698.

[25] M. Q. Slagt, S-E, Stiriba, R. J. M. Klein Gebbink, H. Kautz, H. Frey, G. van Koten, Macromolecules 2002, 35, 5734.

[26] K. R. Kumar, D. E. Brooks, Macromol. Rapid. Commun. 2005, 26, 155.

[27]D. Wan, Q. Fu, J. Huang, J. Appl. Polym. Sci. 2006, 101, 509.

[28]D. Wan, H. Pu, Mater. Lett. 2007, 61, 3404.

[29] Y. Kitajyo, Y. Kinugawa, M. Tamaki, H. Kaga, N. Kaneko, T. Satoh, T. Kakuchi, Macromolecules 2007, 40, 9313.

[30] T. Satoh, M. Tamaki, Y. Kitajyo, T. Maeda, H. Ishihara, T. Imai, H. Kaga, T. Kakuchi. J. Polym. Sci., Part A: Polym. Chem. 2006, 44, 406.

[31] Y. Kitajyo, T. Imai, Y. Sakai, M. Tamaki, H. Tani, K. Takahashi, A. Narumi, H. Kaga, N. Kaneko, T. Satoh, T. Kakuchi, Polymer 2007, 48, 1237.

[32] Y. Kitajyo, Y. Nawa, M. Tamaki, H. Tani, K. Takahashi, H. Kaga, T. Satoh, T. Kakuchi, Polymer 2007, $48,4683$. 